\title{
Индекс раскрытия информации: взаимосвязь с финансовой результативностью
}

\author{
Ильина Ю.Б. ${ }^{4}$, Березинец И.В. ${ }^{5}$, Орлова А.В. ${ }^{6}$
}

В статье представлены результаты исследования, посвященного анализу взаимосвязи между индексом раскрытия информаџии и финансовой результативностью российских компаний. На основе анализа существуюших эмпирических исследований был построен индекс раскрытия информаџии для 64 российских компаний и проведен регрессионный анализ влияния индекса раскрытия информации на финансовую результативность компании. Результаты, к которым пришли авторы, говорят о том, что полученные выводы соотносятся с зарубежными эмпирическими исследованиями, и индекс раскрытия информации на данной выборке не оказывает влияния на финансовую результативность компаний.

$$
\text { JEL: C01, G34. }
$$

Ключевые слова: информачионная открытость, раскрытие информачии, финансовая результивность, индекс раскрытия информации.

\section{Раскрытие информации и финансовые результаты деятельности: анализ эмпирических исследований}

Информационная открытость компании является сегодня неотъемлемой частью качественного корпоративного управления, позволяет снизить асимметрию информации между агентами и принципалами. В этой связи особая роль принадлежит Интернету, который облегчает и ускоряет процесс передачи информации между различными группами стейкхолдеров. Поэтому представляется интересным и востребованным измерить качество информационной прозрачности в российских компаниях через добровольное раскрытие информации на корпоративном сайте. Об актуальности подобного подхода свидетельствует наличие значительного числа эмпирических исследований, посвященных проблемам раскрытия информации и влиянию открытости на финансовую результативность компаний.

Существующие эмпирические исследования можно разделить на две группы: первая группа посвящена проверке влияния информационной прозрачности и открытости компаний на их результативность; вторая группа исследует факторы, влияющие на уровень информационной прозрачности компаний. Что касается методологии исследований, то в подавляющем большинстве работ используется регрессионный анализ.

В работе Сильва, Альвеса [Silva, Alves, 2004] исследуется взаимосвязь между уровнем раскрытия финансовой информации 150 компаний, котируемых на фондовых биржах Бразилии, Аргентины и Мексики, и стоимостью компаний, измеренной коэффициентом Q Тобина. Основные выводы, к которым пришли авторы, говорят о том, что на коэффициент Q Тобина оказывает наибольшее влияние отраслевая принадлежность, а также размер компании. Связь уровня раскрытия информации и рыночной стоимости компаний оказалась значимой, но исследователи отмечают, что данная переменная обладает наименьшей объясняющей силой в модели.

\footnotetext{
${ }^{4}$ Канд. эконом. наук, доцент кафедры финансов и учета Высшей школы менеджмента, СПбГУ

${ }^{5}$ Канд. физ.-матем. наук, доцент кафедры финансов и учета Высшей школы менеджмента, СПбГУ

${ }^{6}$ Финансовый аналитик, аудиторская фирма $3 \mathrm{AO}$ «Профикон»
} 
Фан, Ванг, Цанг [Fan, Wang, Zhang, 2006] исследуют взаимосвязь информационной прозрачности 144 китайских компаний и их конкурентных и стратегических характеристик. Зависимой переменной является уровень раскрытия информации о конкуренции в отрасли. Результаты исследования демонстрируют, что только переменные, характеризующие рыночную конкуренцию, оказывают влияние на результирующую переменную; факторы корпоративного управления и прибыльности компаний не оказали влияния на уровень раскрытия информации.

В соответствии с результатами исследования Ли и Эдди [Liu, Eddie, 2007], китайские компании с наличием иностранного капитала более склонны раскрывать информацию. Получила подтверждение гипотеза о том, что более крупные компании раскрывают больше информации. Прибыльность и раскрытие информации находятся в обратной зависимости чем выше показатель ROE, тем ниже уровень раскрытия. Привлечение международных аудиторов положительно связано с уровнем раскрытия. Что касается китайских компаний без участия иностранного капитала, то для них установлено наличие прямой связи между уровнем концентрации собственности и раскрытием информации. Это объяснено авторами значительной долей государственного владения по сравнению с частным во многих компаниях, поэтому компании склонны раскрывать больше информации, чтобы упрочить уровень государственного доверия.

В работе Фёрта [Firth, 1979] было показано, что крупные фирмы более склонны раскрывать информацию. Чоу, Вонг-Борен [Chow, Wong-Boren, 1987] исследовали взаимосвязь между добровольным раскрытием и размером фирмы, соотношением активов, финансовым рычагом. Эксперты пришли к выводу, что уровень добровольного раскрытия широко варьируется в выборке из 52 мексиканских фирм, а степень раскрытия положительно коррелирует только с размером фирмы. Исследование Кука [Cooke, 1992] демонстрирует, что размер компании, деятельность в обрабатывающем секторе и листинг на зарубежных биржах положительно влияют на уровень раскрытия японских компаний. В работе Нэйзера, Альхатиба, Кэрбхэри [Naser, Alkhatib, Karbhari, 2002] размер компании, уровень долговой нагрузки, маржа и размер аудитора положительно коррелируют с уровнем раскрытия, в то время как ликвидность связана с результирующей переменной отрицательной зависимостью. В исследованиях Лэнга, Ландхольма, Кларксона [Lang, Lundholm ${ }^{7}$, 1993; Clarkson, 1994] было показано, что компании с высокими результатами деятельности имеют стимулы для большего раскрытия информации по сравнению с неэффективными фирмами. Исследование распространения информации через вэб-сайты [Ettredge, 2002], как ожидалось, покажет, прямую связь между количеством информации, расположенной на сайтах, и результативностью. Результаты исследования показали обратную незначимую связь. Можно согласиться, что компании, демонстрирующие хорошие финансовые результаты, склонны подчеркивать свой уровень управления, а также использовать последние технологические разработки в целях развития отношений с инвесторами. Эмпирическое исследование Ричардсона и Уэлкера [Richardson, Welker, 2001] обнаружило положительную связь между раскрытием финансовой информации и финансовыми результатами, измеренными рентабельностью инвестиций (ROI). C другой стороны, компании могут неохотно раскрывать часть информации ради защиты своего конкурентного преимущества. Поэтому нельзя сделать вывод об однозначном положительном либо отрицательном характере связи между уровнем информационной прозрачности компании и результатами ее деятельности.

Исследование Хуфанга и Джангу [Huafang, Jianguo, 2007] изучает уровень раскрытия 559 китайских компаний и демонстрирует, что доля владельцев более чем $5 \%$ акций и присутствие на зарубежных биржах увеличивает уровень раскрытия, в то время как доля

\footnotetext{
${ }^{7}$ Ссылка на исследования [Lang, Lundholm, 1993; Clarkson, 1994; Ettredge, 2002; Richardson, Welker, 2001] содержится y: [Bollen, L. Measuring and explaining the quality of Internet investor relations activities: a multinational empirical analysis / L.Bollen, H. Hassink, G. Bozic // International Journal of Accounting Information Systems. 2006. Vol. 7. - Elsevier B. V., 2005: http://www.sciencedirect.com].
} 
акций, принадлежащих топ-менеджменту, государству и юридическим лицам, не влияет на раскрытие. Увеличение количества независимых директоров положительно влияет на раскрытие, а совмещение постов руководителя и председателя совета директоров (СЕО duality) снижает уровень информационной прозрачности компании.

В работе Боллена, Хэссинка, Боциса [Bollen, Hassink, Bozic, 2006] обследованы вэбсайты 270 котируемых компаний из шести разных стран (Австралии, Бельгии, Франции, Нидерландов, ЮАР, Великобритании). С применением регрессионного анализа авторы пришли к выводу, что переменные, являющиеся прокси размера компании, уровень интернационализации, доля акций, доступных индивидуальным инвесторам, а также влияние окружающей среды положительно коррелируют со степенью раскрытия информации в Интернете. В соответствии с результатами исследования, крупные компании с международным масштабом деятельности интенсивно используют Интернет для общения и информирования инвесторов. Результаты деятельности компании, измеренные доходностью акций и уровнем рентабельности собственного капитала, согласно исследованию, не влияют на уровень добровольного раскрытия. Исследование также не подтвердило связи между уровнем финансового рычага и результирующей переменной, что авторы объясняют тем фактом, что держатели корпоративного долга, кредиторы компании могут использовать другие, частные источники для получения информации о состоянии компании. Гипотеза о взаимосвязи информационной прозрачности компании и уровня технологического прогресса была отвергнута. Была установлена обратная значимая связь между уровнем раскрытия информации и прокси для темпов роста. Что касается влияния окружающей среды, то установлена прямая связь, показывающая, что компании англоамериканской модели (Австралия, Нидерланды, Великобритания) имеют более качественные сайты по сравнению с французскими, бельгийскими и южноафриканскими компаниями. с точки зрения отношений с инвесторами.

В работе Кормьера, Ледокса, Магнана [Cormier, Ledoux, Magnan, 2009] исследуются 189 корпоративных сайтов котируемых канадских компаний, представляющих 80\% капитализации национального фондового рынка. Раскрытие информации в Интернете рассматривается с трех точек зрения: раскрытие, связанное с производственной, социальной и финансовой деятельностью. Было выявлено, что раскрытие информации, связанной с социальной или финансовой деятельностью, влияет на стоимость компании.

Работа Гандиа [Gandía, 2008] исследует информацию о корпоративном управлении 92 котируемых нефинансовых испанских компаний, раскрываемую в Интернете. В результате построения регрессионных моделей автор указывает, что переменные, измеряющие корпоративное управление, не показали связи с уровнем раскрытия информации. Аналогичные выводы сделаны относительно аудита компаний. Отмечается положительная взаимосвязь информационной прозрачности с размером компании, а также с длительностью котирования на фондовом рынке. Относительно отраслевой принадлежности эмитента показано, что компании, оперирующие в отраслях, требующих значительных инвестиций в нематериальные активы, склонны раскрывать большее количество информации (в данной модели - это сектор коммуникаций, информационных услуг). Также выявлено положительное влияние уровня поддержки аналитиков на уровень информационной прозрачности компаний. Это означает, что чем больше аналитиков следят за деятельностью компании, тем выше уровень раскрытия информации.

Боессо, Кумар [Boesso, Kumar, 2006] исследуют факторы, способствующие добровольному раскрытию информации компаниями Италии и США. Результаты исследования демонстрируют, что обе контрольные переменные имеют влияние на результирующую переменную, однако отраслевая принадлежность - в меньшей степени. Волатильность и сложность управления также влияют на уровень информационной прозрачности компаний, независимо от страны происхождения. Однако эти переменные влияют на количество, а не качество раскрываемой информации. Авторы отмечают значимость переменной «взаимоотношения со стэйкхолдерами», также показавшей прямую 
связь с результирующим признаком, и говорят о важности управления взаимоотношениями с заинтересованными лицами, независимо от отраслевого или странового контекста.

Таким образом, в большинстве исследований не установлено зависимости между информационной прозрачностью компаний и показателями финансовой результативности. Исключение составляют работы Сильва, Альвеса и Ли, Эдди [Silva, Alves, 2004; Liu, Eddie, 2007], однако в первой работе информационная прозрачность обладает наименьшей объясняющей силой по сравнению с другими переменными, а во втором исследовании между показателями информационной прозрачности и финансовой результативности найдена отрицательная зависимость. Как правило, значимыми факторами в моделях оказываются размер компании, а также отраслевая принадлежность эмитента; в части работ - уровень долговой нагрузки компании, а также качественные характеристики корпоративного управления (количество независимых директоров, отсутствие совмещения должностей руководителя компании и председателя совета директоров, концентрация собственности).

\section{Измерение индекса раскрытия информации: обзор литературы}

Для проверки влияния информационной прозрачности компаний на показатели их деятельности важным является определение того, каким образом измерять степень информационной открытости компании. Как правило, в зарубежных исследованиях общая методика подразумевает построение одного или нескольких индексов раскрытия информации (Disclosure Index).

Исследования, связанные с построением индекса раскрытия информации, можно условно разделить на две группы. К первой группе относятся исследования, ставящие целью анализ раскрытия информации в различных сферах деятельности компании. При этом индекс раскрытия информации формируется на основе множества показателей; в числе прочего анализируются и характеристики сайта компании. Ко второй группе относятся узконаправленные исследования, посвященные раскрытию информации о корпоративном управлении. Также могут учитываться качественные характеристики сайта, но с точки зрения конечных пользователей и с учетом их потребностей.

Так, в работе Ли и Эдди [Liu, Eddie, 2007] исследуются вопросы, связанные с корпоративной финансовой отчетностью котируемых китайских компаний. Авторы не приводят показатели, на основе которых был составлен индекс раскрытия (DI); указывается лишь, что он составлен на основе 147 показателей. Построение индекса раскрытия основано на применении бинарных переменных (1 - при наличии показателя в проспекте или годовом отчете; 0 - при его отсутствии). В результате сложения набранных показателей компания получала определенный балл. Степень раскрытия - это соотношение набранных компанией баллов к максимально возможным.

Исследование Хуфанга и Джангу [Huafang, Jianguo, 2007] посвящено влиянию структуры собственности и состава совета директоров на добровольное раскрытие информации котируемых китайских компаний. Индекс раскрытия сформирован авторами на основе 30 показателей, разделенных на четыре категории: вводная информация, информация о производственной деятельности, финансовая информация, нефинансовая информация. Информация для составления индекса была заимствована авторами из годовых отчетов компаний. Индекс рассчитан аналогично [Liu, Eddie, 2007], однако полученные баллы не нормируются на максимальный балл, а сразу учитываются в модели.

В работе Кормьера, Ледокса, Магнана [Cormier, Ledoux, Magnan, 2009] содержится 111 критериев, измеряющих степень раскрытия по 9 различным направлениям: мощность вебсайта, финансовые результаты, управленческая информационная система, корпоративное управление, потребительская ценность, человеческий и интеллектуальный капитал, производственная эффективность, рост и развитие, социальная ответственность. В целях данного исследования автор остановится подробнее только на показателях оценки 
корпоративного управления. К ним Кормьер, Ледокс, Магнан [Cormier, Ledoux, Magnan, 2009] относят стратегическое управление, информацию о менеджерах, совете директоров, аудиторах, структуре собственности. Все представленные показатели оценивались по шкале от 1 до 3.

Ко второй группе исследований относится работа Боллена, Хэссинка, Боциса [Bollen, Hassink, Bozic, 2006], в которой исследуется использование компаниями Интернета для развития взаимоотношений с инвесторами (Investor Relations, IR) посредством анализа качественных составляющих веб-сайтов компаний. Качество корпоративных сайтов авторы измеряют по следующим пяти направлениям: годовые и квартальные отчеты в сети Интернет, пресс-релизы и иная информация в Интернете, удобство просмотра в Интернете, прямой контакт через электронный ящик либо подписка, видео- или аудиозаписи и участие во встречах онлайн. Таким образом, индекс строится на основе показателей по пяти категориям. Набранные баллы суммируются и взвешиваются. Авторы применяют результаты исследования Битти, Пратт [Beattie, Pratt $^{8}$, 2003], которые показали, что точки зрения тех, кто подготавливает информацию, и конечных пользователей относительно содержания и характеристик публикуемой информации значительно различаются. По этой причине структура и информация корпоративных сайтов не всегда отражают требования потенциальной целевой группы.

Исследование Гандиа [Gandía, 2008] посвящено раскрытию информации о корпоративном управлении котируемых испанских компаний в Интернете. Автор создает три индекса раскрытия: индекс раскрытия корпоративного управления в годовых отчетах; индекс, учитывающий информацию, доступную на веб-сайте Испанской Комиссии по национальному рынку ценных бумаг (Spanish National Securities Market Comission); индекс раскрытия корпоративного управления в Интернете, измеряемый информацией, содержащейся на сайте каждой компании. Все три индекса имеют как общие показатели, так и показатели, уникальные для каждого из них. Всего автор выделяет 32 показателя, разделенных по четырем категориям: раскрытие информации о совете директоров, ежегодное собрание акционеров, структура собственности, другая информация, относящаяся к управлению.

\section{Методология эмпирического исследования}

Методика, примененная для построения индекса раскрытия, аналогична методике Ли и Эдди. Индекс раскрытия информации, построенный авторами, состоит из 22 показателей, отражающих раскрытие информации на корпоративном сайте компании по таким категориям, как информация об управлении (КУ), финансовая информация (ФИН), удобство просмотра в Интернете (ИНТЕРНЕТ), информация о деятельности компании (КОМПАНИЯ). Следуя методике, использованной в работе Боллена, Хэссинка, Боциса, в соответствии с которой каждая категория индекса раскрытия получила определенный вес в соответствии со степенью важности для инвестора, в представленном здесь исследовании индекс раскрытия рассчитывался как взвешенная сумма баллов, набранных компанией по каждой категории, по следующей формуле:

$$
\begin{aligned}
& \text { Индекс раскрытия }_{\text {взеш. }}=0,4 \times К У+0,3 \times Ф И Н+0,15 \times \text { ИНТЕРНЕТ + } \\
& +0,15 \times \text { КОМПАНИЯ }
\end{aligned}
$$

Необходимо отметить, что в исследовании применялся и невзвешенный индекс раскрытия информации, однако все модели, построенные с его использованием, оказались незначимыми.

\footnotetext{
${ }^{8}$ Ссылка на работу содержится у: [Bollen, L. Measuring and explaining the quality of Internet investor relations activities: a multinational empirical analysis / L.Bollen, H. Hassink, G. Bozic // International Journal of Accounting Information Systems. 2006. Vol. 7. - Elsevier B. V., 2005: http://www.sciencedirect.com].
} 
Детальная структура индекса раскрытия информации и его измерение представлены в Приложении. К информации об управлении относятся сведения о совете директоров (состав и должности), информация о независимых директорах, информация о комитетах совета директоров (названия комитетов и их функции), информация по вознаграждениям директорам и высшему менеджменту, сведения о составе и членах правления, информация о структуре акционерного капитала, информация об аффилированных лицах, наличие информации о последнем собрании акционеров (указание на дату проведения и принятые решения), раскрытие информации об управлении на корпоративном сайте. Последний показатель введен в исследование для того, чтобы авторы имели возможность присвоить более высокие баллы компаниям, раскрывающим информацию на корпоративном сайте, а не в годовых отчетах. Определенные сложности возникли также при измерении показателя, характеризующего наличие информации о структуре акционерного капитала, поскольку некоторые компании указывают только номинальных держателей, а некоторые - не указывают вовсе, какие юридические лица являются номинальными держателями, а какие реальными владельцами. В подобной ситуации авторами присваивался балл $1 / 2$, при указании только на номинальных держателей. Если же не был указан статус владельца, делалось предположение, что он не является номинальным держателем.

Все показатели индекса раскрытия являются, как правило, бинарными переменными, принимающими значение, равное 1 , при наличии соответствующей информации, 0 - при ее отсутствии. Некоторые переменные являются порядковыми, помимо вышеуказанных значений принимают также значение $1 / 2$ при частичном наличии информации (например, при наличии указания о дате проведения последнего собрания акционеров, но при отсутствии информации о принятых решениях). Эти переменные были включены в модель для того, чтобы характеризовать тенденцию к раскрытию информации. Аналогичная методика применена и для количественного измерения показателей других категорий индекса раскрытия.

К показателям, отражающим раскрытие финансовой информации, были отнесены следующие: наличие годовой финансовой отчетности за последние три года, наличие квартальных отчетов за последний год (2007 г.), информация по дивидендной политике, информация о кредитной истории эмитента, информация о прочих ценных бумагах, информация об аудиторах. Отметим, что в показателе «Наличие годовой финансовой отчетности за последние три года» учитывалось наличие годового бухгалтерского баланса, отчета о прибылях и убытках, отчета об изменениях капитала, отчета о движении денежных средств за 2005, 2006 и 2007 гг. К категории «Удобство просмотра в Интернете» были отнесены: удобство работы с сайтом компании, наличие сервиса «вопрос-ответ», а также обновляемого финансового календаря. Удобство работы с сайтом предполагало выполнение четырех требований: удобство просмотра документов (все документы в надлежащем качестве); возможность перехода по ссылкам (все ссылки активны); доступ к информации на сайте (финансовая отчетность представлена на этом же сайте, нет необходимости выискивать «еще один» сайт, используемый эмитентом для раскрытия информации); наличие отдельного раздела по работе с инвесторами/корпоративному управлению. Наличие сервиса «вопрос-ответ» учитывало также и наличие сервиса часто задаваемых вопросов (FAQ), из которого зачастую можно сразу получить необходимую информацию. Также важно было учесть наличие обновляемого финансового календаря, поскольку у многих компаний есть указание на интересующие инвестора события, однако зачастую данный сервис не является обновляемым. Информация об управлении включала наличие годового отчета, раскрытие отчетов, касающихся корпоративной социальной ответственности, наличие информации о реструктуризации и иных существенных фактах, наличие доступа к уставу. При анализе годового отчета аналогично показателю, измеряющему наличие годовой финансовой отчетности, учитывались годовые отчеты за 2005, 2006, 2007 гг. 


\section{Результаты исследования}

Для того чтобы исследовать влияние информационной открытости российских компаний на их финансовую результативность, было решено применить регрессионный анализ. Подобная методология используется в большинстве зарубежных исследований [Bollen, Hassink, Bozic, 2006; Liu, Eddie, 2007; Gandı'a, 2008; Cormier, Ledoux, Magnan, 2009].

Выборка исследования делалась из 64 компаний - российских открытых акционерных обществ (OAO), как котируемых на российском и/или зарубежных фондовых рынках, так и не котируемых. При этом компании, листингуемые на биржах, составляют 21\% (14 компаний). Выборка была сформирована на основе компаний, которые приняли участие в «Исследовании особенностей корпоративного управления крупных компаний в Российской Федерации», проводившегося Высшей школой менеджмента Санкт-Петербургского государственного университета в 2007 г. при участии Всероссийского центра изучения общественного мнения (ВЦИОМ). В процессе работы автором было обследовано порядка 80 корпоративных сайтов, на основе чего формировался индекс раскрытия информации для каждой компании.

Отраслевое распределение компаний выборки представлено на рис. 1.

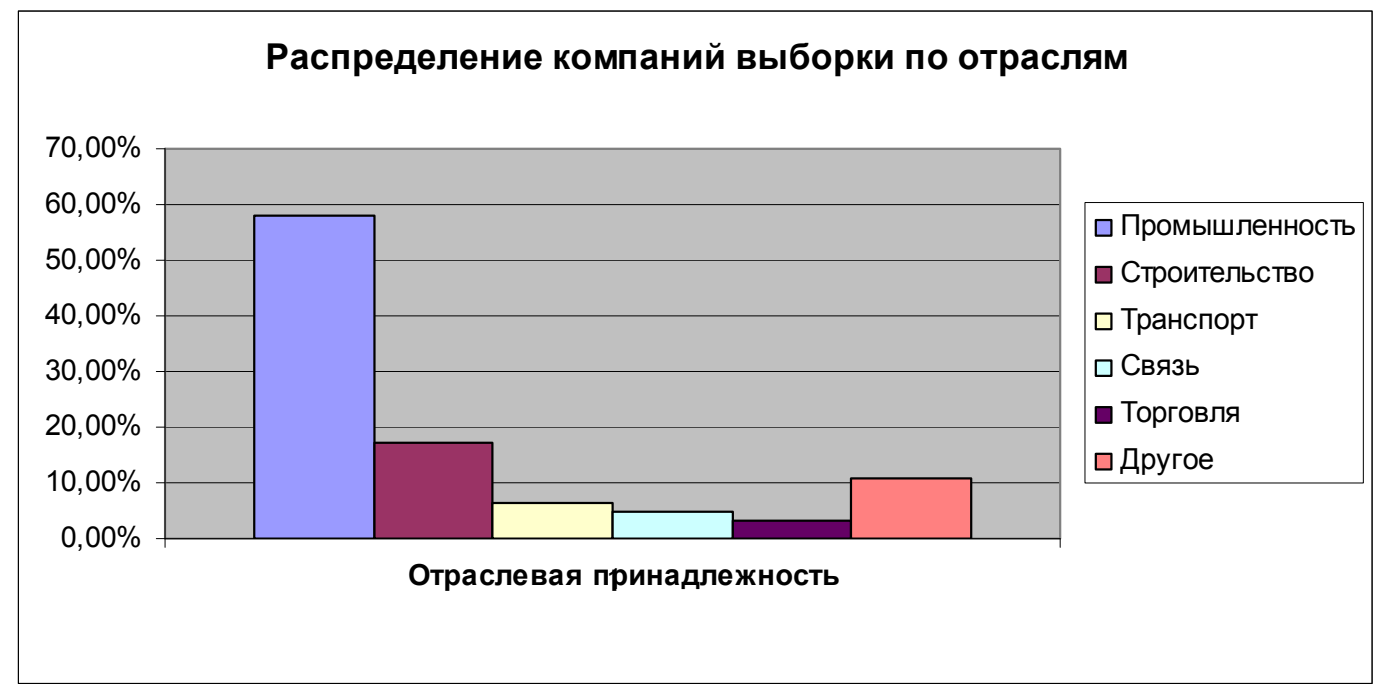

Рис. 1. Распределение компаний выборки по отраслям

Что касается географического распределения компаний, то в выборку вошли компании из 13 регионов Российской Федерации, или 6 федеральных округов, - по 12 компаний из Центрального, Южного и Приволжского федеральных округов; 11 компаний из Сибирского, 10 - из Уральского и 7 - из Северо-Западного федеральных округов. Среднее значение выручки для компаний выборки - 22,4 млрд руб.

Целью исследования является установление зависимости между информационной открытостью компаний, показателем которой в данном исследовании является индекс раскрытия информации, и финансовой результативностью компаний.

Авторы данного исследования выдвинули следующую гипотезу о влиянии индекса раскрытия информации на рентабельность продаж компании:

Гипотеза. Рост индекса раскрытия информации положительно влияет на рентабельность продаж компании.

Для тестирования сформулированной гипотезы была построена следующая линейная многофакторная модель:

$$
\begin{aligned}
& \mathrm{y}=\beta_{0}+\beta_{1} x_{1}+\beta_{2} x_{2}+\beta_{3} x_{3}+\ldots+\beta_{9} x_{9}+\varepsilon, \\
& \text { где } \\
& \text { у - рентабельность продаж (ROS); } \\
& \mathrm{x}_{1} \text { - индекс раскрытия информации; }
\end{aligned}
$$


$\mathrm{x}_{2}$ - коэффициент соотношения заемных и собственных средств;

$\mathrm{x}_{3}-$ период оборота активов;

$\mathrm{x}_{4}, \ldots, \mathrm{x}_{8}$ - переменные, характеризующие отраслевую принадлежность компании;

$\mathrm{x}_{9}$ - логарифм активов;

$\beta_{0}, \beta_{1}, \beta_{2}, \beta_{3}, \ldots, \beta_{9}$ - неизвестные параметры;

$\varepsilon-$ случайная составляющая, характеризующая не учтенные в модели факторы.

Для $\varepsilon$ предполагается соблюдение условий Гаусса - Маркова.

Укажем, каким образом измерялись переменные модели.

- Степень информационной открытости компании, измеряемая индексом раскрытия информации. Фактор используется во многих работах [Cormier, Ledoux, Magnan, 2009; Liu, Eddie, 2007; Huafang, Jianguo, 2007; Bollen, Hassink, Bozic, 2006; Álvarez, Sánchez, Domínguez, 2008]. Следует отметить, что в процессе исследования использовался и невзвешенный индекс раскрытия информации, однако модели, построенные с применением такой зависимой переменной, оказались незначимыми и были исключены из дальнейшего рассмотрения.

- Структура капитала, характеризуемая коэффициентом соотношения заемных и собственных средств на 2007 г. Данные для каждой компании были получены из электронной базы данных СПАРК (Система профессионального анализа рынков и компаний). Аналогичный фактор используется также у других авторов [Cormier, Ledoux, Magnan, 2009; Bollen, Hassink, Bozic, 2006].

- Деловая активность характеризуется периодом оборота активов. Переменная вычисляется как соотношение 360 дней к периоду оборота активов компании на 2007 г. Данные для каждой компании были получены из электронной базы данных СПАРК (Система профессионального анализа рынков и компаний).

В качестве контрольных переменных использовались:

- Отраслевая принадлежность компании (фактор применяется у разных авторов [Liu, Eddie, 2007; Huafang, Jianguo, 2007; Bollen, Hassink, Bozic, 2006; Álvarez, Sánchez, Domínguez, 2008]). Было выделено 8 переменных: промышленность, строительство, торговля, транспорт, связь, сфера услуг, сельское хозяйство и ЖКХ. Так как компании последних трех отраслей не присутствовали в выборке, то эти переменные были удалены из модели.

- Размер компании (фактор применяется в различных исследованиях [Liu, Eddie, 2007; Huafang, Jianguo, 2007; Bollen, Hassink, Bozic, 2006; Álvarez, Sánchez, Domínguez, 2008; Cormier, Ledoux, Magnan, 2009]). В качестве прокси планировалось применять либо логарифм численности занятых, либо логарифм активов компании. В результате тестирования модели с применением логарифма численности занятых оказались незначимыми; было решено остановиться на логарифме активов. Переменная вычисляется как натуральный логарифм активов. Данные взяты из электронной базы данных СКРИН (Системы комплексного раскрытия информации).

Специфика модели состоит в том, что большинство компаний выборки не являются публичными, поэтому авторы пришли к необходимости использования показателей, которые позволяли бы оценить стоимость непубличных компаний. В качестве зависимой переменной первоначально использовался показатель рентабельности собственного капитала (Return on Equity, ROE) аналогично многим исследованиям [Ismail, 2002; Bollen, Hassink, Bozic, 2006; Liu, Eddie, 2007; Gandía, 2008], а также фундаментальная стоимость компании в расчете на одну акцию аналогично методике, использованной в работе отечественных ученых [Волков, Березинец, 2006]. Однако модели с применением подобных переменных получились незначимыми, поэтому было принято решение о применении в качестве результирующей переменной рентабельности продаж (Return on sales, ROS). 
Результаты статистического оценивания модели представлены в таблице 1.

\begin{tabular}{|l|l|}
\hline \multicolumn{1}{|c|}{ Вывод итогов по модели } & Оценки параметров \\
\hline У-пересечение & $-0,361$ \\
\hline Индекс раскрытия информации $\left(\mathrm{x}_{1}\right)$ & $-0,0006$ \\
\hline Долг/СК $\left(\mathrm{x}_{2}\right)$ & $-0,003$ \\
\hline Период оборота активов $\left(\mathrm{x}_{3}\right)$ & 0,0016 \\
\hline Промышленность $\left(\mathrm{x}_{4}\right)$ & $-0,002$ \\
\hline Строительство $\left(\mathrm{x}_{5}\right)$ & $-0,0208$ \\
\hline Торговля $\left(\mathrm{x}_{6}\right)$ & $-0,0003$ \\
\hline Транспорт $\left(\mathrm{x}_{7}\right)$ & 0,0319 \\
\hline Связь $\left(\mathrm{x}_{8}\right)$ & $-0,0037$ \\
\hline $\ln$ Активы $\left(\mathrm{x}_{9}\right)$ & $0,023 * * *$ \\
\hline F-статистика $\left(\mathrm{Z}^{*}\right)$ & 2,27 \\
\hline Граница критической области $\mathrm{K}_{2}$ & 2,059 \\
\hline Коэффициент детерминации $\mathrm{R}^{2}$ & 0,275 \\
\hline$\overline{R^{2}}{ }_{\text {нормир }}$ & 0,154 \\
\hline
\end{tabular}

Таблица 1

***Фактор значим на уровне 0,01

Как видно из таблицы, значение выборочной статистики $\mathrm{Z}^{*}>\mathrm{K}_{2}$, поэтому принимается альтернативная гипотеза и делается вывод о статистической значимости модели. На 27,5\% изменение результирующей переменной может быть объяснено за счет линейной регрессии. Все факторы в модели, кроме размера компании, оказались статистически незначимыми.

Таким образом, на данной выборке компаний мы не нашли подтверждения предположения о том, что имеет место взаимосвязь между индексом раскрытия информации и рентабельностью продаж компаний и что рост индекса раскрытия информации положительно влияет на рентабельность продаж компании.

С точки зрения авторов, данный факт объясняется в первую очередь особенностями формирования выборки компаний, в частности, преобладанием компаний, чьи акции не котируются на фондовых биржах.

Однако нельзя не отметить, что к аналогичным выводам об отсутствии взаимосвязи между двумя указанными показателями приходят и авторы зарубежных эмпирических исследований.

\section{Заключение}

Вопрос взаимосвязи информационной открытости и финансовой результативности, с одной стороны, является весьма актуальным и вызывает значительный интерес у зарубежных исследователей, что подтверждается наличием достаточно большого количества эмпирических исследований в данной области. С другой стороны, для российского рынка тема информационной прозрачности не раскрыта. Кроме того, отечественные компании в целом характеризуются достаточно высокой степенью непрозрачности. Именно по этой причине данная работа основана, в первую очередь, на применении зарубежного опыта, однако, при построении индекса раскрытия, а также выбора факторов для моделей, авторы стремились учитывать российскую специфику.

В данной работе рассмотрены основные эмпирические исследования, посвященные проблемам раскрытия информации и исследованию взаимосвязи информационной открытости компаний и их финансовой результативности. При этом в большинстве исследований используется методика построения индекса раскрытия информации (Disclosure Index), основанного на анализе корпоративных сайтов компаний. Полученные значения используются в дальнейшем для построения регрессионной модели, исследующей 
взаимосвязь между информационной прозрачностью и финансовой результативностью компаний. Как правило, значимыми факторами, оказывающими влияние на финансовую результативность в рассматриваемых эмпирических исследованиях, является размер компании и ее отраслевая принадлежность. В этом смысле результаты данного исследования соотносятся с результатами зарубежных эмпирических исследований.

Направление дальнейших исследований может быть связано с включением в выборку только котируемых компаний, к тому же ведущих деятельность на зарубежных рынках, а также с более выверенным построением индекса раскрытия, учитывающим комплексное раскрытие информации эмитентами через различные источники либо увеличение числа показателей, входящих в индекс раскрытия.

\section{Список литературы}

1. Волков Д. Л. Управление ценностью: проблема достоверности бухгалтерских моделей оценивания [Электронный ресурс] / Волков Д. Л., Березинец И. В. // Вестник Санкт-Петербургского университета. Серия 8. Менеджмент. 2006. Вып. 4. - Режим доступа: http://vestnikmanagement.pu.ru/archive/pdf/276.pdf.

2. Álvarez, I. G. Voluntary and compulsory information disclosed online: The effect of industry concentration and other explanatory factors / I. G. Álvarez, I. M. Sánchez, L. R. Domínguez, Online Information Review. 2008. Vol. 32. Iss. 5. - Emerald Group Publishing Limited: www.emeraldinsight.com.

3. Boesso, G. Drivers of corporate voluntary disclosure: a framework and empirical evidence from Italy and the United States // G. Boesso, K. Kumar, Accounting, Auditing \& Accountability Journal. 2007. Vol. 20, Iss. 2. - Emerald Group Publishing Limited: www.emeraldinsight.com.

4. Bollen, L. Measuring and explaining the quality of Internet investor relations activities: a multinational empirical analysis / L.Bollen, H. Hassink, G. Bozic, International Journal of Accounting Information Systems. 2006. Vol. 7. - Elsevier B. V., 2005: http://www.sciencedirect.com.

5. Chow, C.W. Voluntary financial disclosure by Mexican Corporations / C.W. Chow, A. Wong-Boren, Accounting Review. 1987. Vol. 62. Iss. 3. - Emerald Group Publishing Limited: www.emeraldinsight.com.

6. Cooke, T.E. The effect of size, stock market listing and industry type on disclosure in the annual reports of Japanese listed corporations / T.E. Cooke, Accounting \& Business Research. 1992. Vol. 22, Iss. 87. - Emerald Group Publishing Limited: www.emeraldinsight.com.

7. Cormier, D. The use of Web sites as a disclosure platform for corporate performance / D. Cormier, M. Ledoux, M. Magnan, International Journal of Accounting Information Systems. 2009. Vol. 10. - Elsevier B. V., 2005: http://www.sciencedirect.com.

8. Fan, Z. Corporate Competitive Strategy and Voluntary Disclosure / Z. Fan, L. Wang, J. Zhang, Social Science Electronic Publishing, Inc.: http://www.ssrn.com.

9. Firth, M.A. The effect of size, stock market listings, and auditors on voluntary disclosure in corporate annual reports / M.A. Firth, Accounting \& Business Research. 1979. Vol. 9. Iss. 36. - Emerald Group Publishing Limited: www.emeraldinsight.com.

10. Gandía, J. Determinants of internet-based corporate governance disclosure by Spanish listed companies / J. Gandía, Online Information Review. 2008. Vol. 32. Iss. 6. - Emerald Group Publishing Limited: www.emeraldinsight.com.

11. Huafang, X. Ownership structure, board composition and corporate voluntary disclosure. Evidence from listed companies in China / X. Huafang, Y. Jianguo, Managerial Auditing Journal. 2007. Vol.22. Iss. 6. - Emerald Group Publishing Limited: www.emeraldinsight.com. 
12. Liu, J. Determinants of disclosures of A-, B- and H-share companies / J. Liu, I. A.Eddie, Asian Review of Accounting. 2007. Vol. 15. Iss. 1. - Emerald Group Publishing Limited: www.emeraldinsight.com.

13. Naser, K. Empirical evidence on the depth of corporate information disclosure in developing countries: the case of Jordan / K. Naser, K. Alkhatib, Y. Karbhari, International Journal of Commerce \& Management. 2002. Vol. 12. - Emerald Group Publishing Limited: www.emeraldinsight.com.

14. Silva, W. M. The Voluntary Disclosure of Financial Information on the Internet and the Firm Value Effect in Companies across Latin America / W. M. da Silva, L. A. de Lira Alves, Social Science Electronic Publishing, Inc.: http://www.ssrn.com.

\section{Приложение}

Структура индекса раскрытия информации

\begin{tabular}{|c|c|}
\hline Показатель & Измс \\
\hline $\begin{array}{l}\text { Категория 1. Информациия об } \\
\text { управлении }\end{array}$ & \\
\hline я о совете директоров & $\begin{array}{l}1 \text { - если есть информация о составе СД и должностях, } \\
\text { занимаемых его членами; 1/2 - если есть не вся } \\
\text { информация; } 0 \text { - в ином случае. }\end{array}$ \\
\hline $\begin{array}{l}\text { Информация о независимых } \\
\text { директорах }\end{array}$ & $\begin{array}{l}1 \text { - если есть указание на независимость директоров; } 0 \text {-в } \\
\text { ином случае. }\end{array}$ \\
\hline $\begin{array}{l}\text { Информация о } \quad \text { комитетах } \\
\text { совета директоров }\end{array}$ & $\begin{array}{l}\text { и перечислены комитеты СД и их функции; 1/2- } \\
\text { ь не вся информация; } 0 \text { - в ином случае. }\end{array}$ \\
\hline Информация п по & 1 - если есть информация по вознаграждениям директорам \\
\hline $\begin{array}{l}\text { вознаграждениям директорам } \\
\text { и высшему менеджменту }\end{array}$ & $\begin{array}{l}\text { и высшему менеджменту; } 1 / 2-\text { если есть не вся } \\
\text { информация; } 0 \text { - в ином случае. }\end{array}$ \\
\hline $\begin{array}{l}\text { Сведения о составе и членах } \\
\text { правления }\end{array}$ & $\begin{array}{l}\text { зедения о составе правления и занимаемых } \\
\text { Iжностях; 1/2- если есть не вся информация; } \\
\text { ae. }\end{array}$ \\
\hline $\begin{array}{l}\text { Информация о структуре } \\
\text { акционерного капитала }\end{array}$ & $\begin{array}{l}\text { ы основные собственники компании; } \\
\text { олько номинальные держатели либо }\end{array}$ \\
\hline $\begin{array}{l}\text { Информация } \\
\text { аффилированных лицах }\end{array}$ & $\begin{array}{l}\text { и информации об аффилированных лицах; } 0 \\
\text { е. }\end{array}$ \\
\hline $\begin{array}{lr}\text { Наличие } & \text { информации } \quad \text { о } \\
\text { последнем } & \text { собрании } \\
\text { акционеров } & \end{array}$ & $\begin{array}{l}1 \text { - если есть указание на дату проведения последнего } \\
\text { собрания акционеров и указаны решения, принятые на } \\
\text { последнем собрании; } 1 / 2 \text { - если указана не вся информация; } \\
0 \text { - в ином случае. }\end{array}$ \\
\hline $\begin{array}{l}\text { Раскрытие информации об } \\
\text { управлении на корпоративном } \\
\text { сайте }\end{array}$ & $\begin{array}{l}1 \text { - если вся информация данной категории доступна на } \\
\text { корпоративном сайте; } 1 / 2-\text { если часть информации } \\
\text { доступна на корпоративном сайте; } 0 \text { - если информация } \\
\text { отсутствует на корпоративном сайте. }\end{array}$ \\
\hline
\end{tabular}




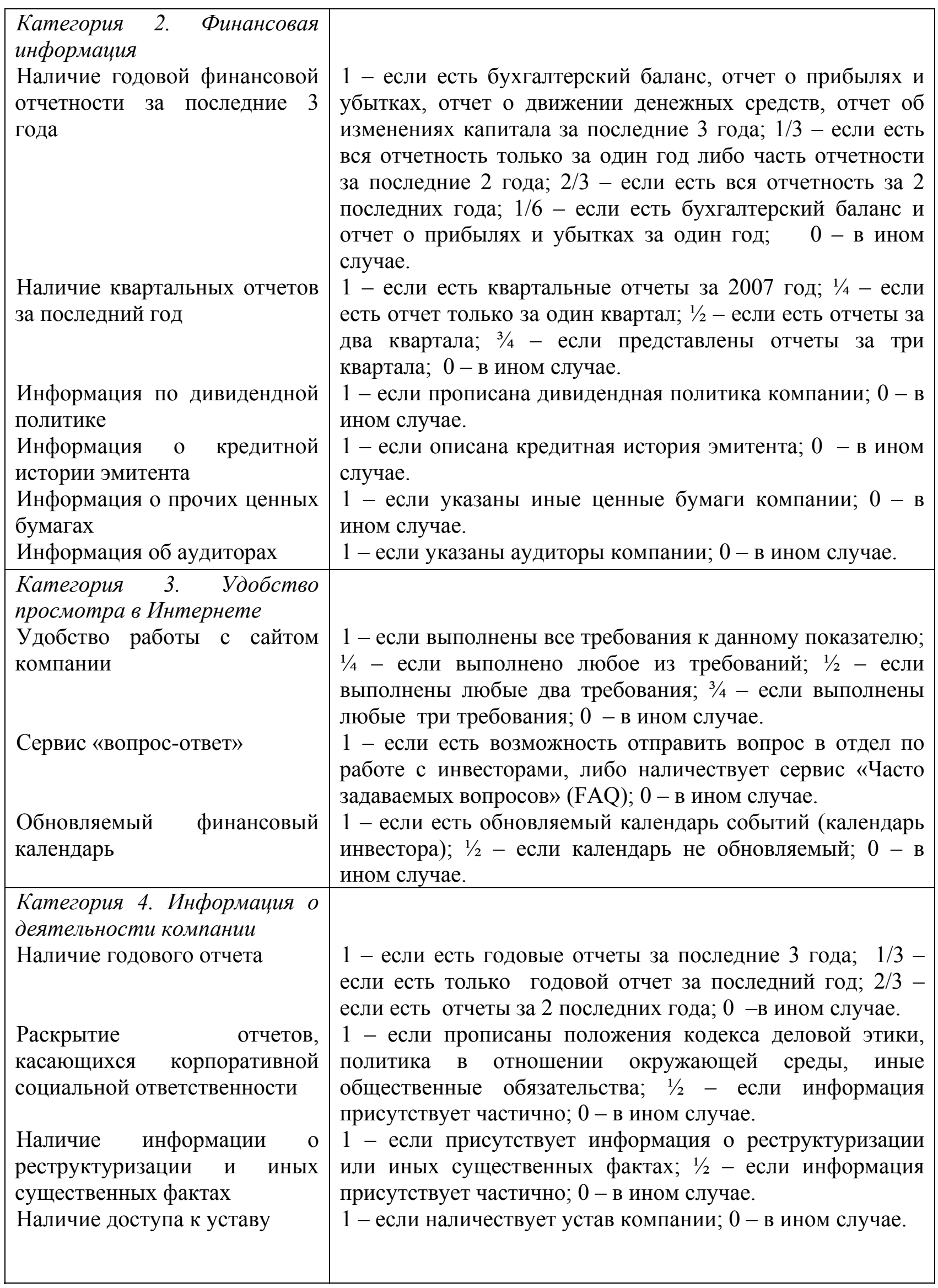

